\title{
QRS Complex Duration is a Marker of Reperfusion in Patients Presenting with Acute ST Segment Elevation Myocardial Infarction
}

Gehan Magdy ${ }^{1 *}$, Hesham El Ashmawy1, Kamal Mahmoud² and Asmaa Youssef ${ }^{2}$

${ }^{1}$ Department of Cardiology and Angiology, Faculty of Medicine, Alexandria University, Egypt

${ }^{2}$ Unit of Cardiology and Angiology, Medical Research Institute, Alexandria University, Egypt

\begin{abstract}
Background: Acute myocardial ischemia decreases electrical conduction velocity through the ischemic myocardium, the aim of the study is to evaluate the value of the change in QRS complex duration as a marker of reperfusion in patients presenting with ST segment elevation myocardial infarction.

Methods: The study included 100 patients presented with ST segment elevation myocardial infarction, 50\% treated with fibrinolysis and $50 \%$ with primary Percutaneous intervention, all patients were subjected to 12 lead electrocardiography with measurement of QRS complex duration (in millisecond) on admission, sixty and ninety minutes post reperfusion, coronary angiography was done to all patients and they were divided into two groups according to myocardial blush grade, group A (55\%) with normal reperfusion (grade 2 and 3 ) and group B (45\%) with impaired reperfusion (grade 0 and 1 ).

Results: We found that the admission QRS duration didn't differ in the two groups ( $p=0.859)$, and QRS complex duration was found to be significantly shorter in group $A$ at both 60 and 90 min post reperfusion ( $<<0.001$ for both) and found a strong positive correlation between myocardial blush grade and QRS complex narrowing at both 60 min and 90 min post reperfusion respectively $(r=0.731, p<0.001$ and $r=0.739, p<0.001)$. A cut off 10 msec was determined to be the best QRS complex narrowing duration for prediction of reperfusion at both 60 and 90 min post reperfusion with $100 \%$ sensitivity, and a specificity of $(43.64 \%$ and $58.18 \%)$ at $60 \mathrm{~min}$ and 90 min post reperfusion respectively.
\end{abstract}

Conclusion: QRS duration changes post reperfusion is strongly correlated to myocardial reperfusion in patients presenting with ST segment elevation myocardial infarction.

Keywords: QRS complex; Acute myocardial infarction; Myocardial blush grade

\section{Introduction}

Acute ST segment elevation myocardial infarction (STEMI) represents the most lethal form of acute coronary syndrome [1], 12 lead electrocardiogram (ECG) is pivotal in providing the diagnosis and subsequent therapeutic decision to initiate thrombolytic therapy, or primary percutaneous coronary intervention (PCI) $[2,3]$. The primary goal of reperfusion therapy in acute STEMI is to achieve complete and sustained myocardial reperfusion in a timely fashion. Although the post reperfusion electrocardiogram has shown promise as a noninvasive reperfusion marker, electrocardiographic assessment of reperfusion is traditionally based solely on changes of the ST segment, the prolongation of the QRS duration in STEMI has been identified as an independent predictor of adverse outcome, reperfusion therapy was reported to cause decreases in QRS duration and mortality in STEMI $[4,5]$. This study aimed to evaluate the value of the change in QRS complex duration as a marker of reperfusion in patients with STEMI.

\section{Patients and Methods}

An informed consent was obtained from all patients. And the study was approved by the ethical committee. The study is a prospective one carried on 100 patients presented with acute STEMI admitted to cardiology department, from first of August 2014 to end of February 2015, STEMI was defined as typical chest pain of more than $30 \mathrm{~min}$ duration with ST-segment elevation $>1 \mathrm{~mm}$ in at least two consecutive precordial or inferior leads [2]. The study was approved by local ethical committee, all patients included should be within $12 \mathrm{~h}$ from the onset of symptoms, $50 \%$ of them had received fibrinolytic therapy using streptokinase in a dose of 1.5 million units over one hour then the patients referred for doing control coronary angiography within $24 \mathrm{~h}$ after successful fibrinolysis, and 50\% underwent primary PCI, Patients that were excluded from the study previous coronary artery bypass grafting, previous PCI, or old myocardial infarction, ECG with bundle branch block, electrolytes abnormalities, left ventricular hypertrophy, or severe ST segment elevation obscuring J point identification, patients with history of recent haemorrhagic stroke, active bleeding or bleeding diathesis, recent history of trauma or major surgery within one month. All patients were subjected to the following investigations including full history taking, clinical examination and cardiac biomarkers CK$\mathrm{MB}$ and troponin I.

\section{Echocardiography}

Transthoracic echocardiography was done for all patients, left ventricular ejection fraction (LVEF) was measured by the modified Simpsons method, and the 17-segment model was used for scoring the severity of segmental wall motion abnormalities by wall motion score index (WMSI) according to the American Society of Echocardiography [6].

*Corresponding authors: Gehan Magdy, Department of Cardiologyand Angiology, Faculty of Medicine, Alexandria University, Egypt, Tel: 00201227108669; E-mail: gehanmagdy@hotmail.com

Received April 08, 2017; Accepted May 17, 2017; Published May 22, 2017

Citation: Magdy G, El Ashmawy H, Mahmoud K, Youssef A (2017) QRS Complex Duration is a Marker of Reperfusion in Patients Presenting with Acute ST Segment Elevation Myocardial Infarction. J Cardiovasc Dis Diagn 5: 277. doi: 10.4172/23299517.1000277

Copyright: ( 2017 Magdy G, et al. This is an open-access article distributed under the terms of the Creative Commons Attribution License, which permits unrestricted use, distribution, and reproduction in any medium, provided the original author and source are credited. 
Citation: Magdy G, El Ashmawy H, Mahmoud K, Youssef A (2017) QRS Complex Duration is a Marker of Reperfusion in Patients Presenting with Acute ST Segment Elevation Myocardial Infarction. J Cardiovasc Dis Diagn 5: 277. doi: 10.4172/2329-9517.1000277

\section{Electrocardiogram}

Twelve leads electrocardiogram with a paper speed of $50 \mathrm{~mm} / \mathrm{s}$ and amplification of $10 \mathrm{~mm} / \mathrm{v}$ was done on admission and was repeated at sixty and ninety minutes following fibrinolysis, or PCI, ST segment resolution using ST-segment deviation score which was calculated by adding the number of millimeters that the ST segment deviates (elevation or depression) from the isoelectric line in all 12 ECG leads on admission and after reperfusion at $60^{\text {th }} \mathrm{min}$ and $90^{\text {th }} \mathrm{min}$ [7-11], and QRS duration was measured manually from the onset to the J-point in three consecutive beats in the infarct related leads on admission and after reperfusion at $60^{\text {th }}$ and $90^{\text {th }} \min [12-14]$.

\section{Angiographic evaluation}

Angiographic evaluation was done to all patients whether treated by primary PCI or received fibrinolytic therapy that followed by coronary angiography at a mean of 3 days after the myocardial infarct. Using the Thrombolysis in Myocardial Infarction (TIMI) flow classification. Primary PCI is considered successful when TIMI-3 flow without significant residual stenosis $(>20 \%)$ in the infarct related artery (IRA) is achieved. Myocardial blush grade (MBG) is based on the visual assessment of contrast opacification of the myocardial territory subtended by the IRA.MBG grades 0 and 1 are taken as indicator of injured microvasculature (impaired reperfusion) and MBG grades 2 and 3 as indicators of preserved microvasculature (successful reperfusion) $[15,16]$.

\section{Statistical analysis}

Continuous variables were presented as mean \pm SD and were compared by Student's t-test or Mann-Whitney $U$ test for variables with or without normal distribution, respectively. Categorical variables were expressed as percentages and evaluated with a Chi square test or Fisher's exact test. The Spearman correlation coefficient was calculated to evaluate the association between 2 continuous variables. In order to determine the predictive impact of post-angioplasty QRS duration narrowing on assessment of reperfusion status, receiver operating characteristics (ROC) analyses was performed and best cut off value was determined and at that point sensitivity and specificity were determined. Statistical analysis was performed using SPSS 20 (Chicago, IL, USA). A probability value of $\mathrm{p}<0.05$ was considered significant.

\section{Results}

The 100 patients included in the study were divided into two main groups according to the reperfusion status detected by $M B G$, group $A$ $(n=55)$ with MBG 2-3 and group B $(n=45)$ with MBG 0-1.

\section{Baseline clinical, echocardiographic and angiographic characteristics of the patients}

As shown in Table 1, patients in group B were significantly older than group $\mathrm{A}$, the two groups were similar in terms of gender, smoking habits, history of hypertension and diabetes mellitus. By examination the heart rate, and blood pressure did not differ between the two groups, however group A had a higher Killip class I than group B which had a higher Killip class II-III. The cardiac biomarkers troponin I and CKMB were significantly higher in group B. As regard the method of reperfusion we found the majority of patients (70.9\%) in group A did primary PCI, while in group B only $(24.4 \%)$ who did primary PCI, and a significant differences was detected between the two groups in terms of the pain to needle time as patients in group B had a longer pain to needle interval compared to group A. Regarding echocardiography the patients in group $\mathrm{B}$ had a significantly lower EF and higher wall motion score index in comparison to group A. The angiographic characteristics of both groups are shown in Table 2 .

\section{Electrocardiographic findings}

When the two groups compared the in terms of electrocardiographic parameters (Table 3), they had a similar QRS duration on admission $(78.0 \pm 11.30$ vs. $78.64 \pm 11.72 \mathrm{msec}, \mathrm{p}=0.859$ respectively), QRS duration was found to be longer in group B compared to group A at both the $60^{\text {th }}$ min ECG $(78.44 \pm 11.37$ vs. $66.55 \pm 9.71 \mathrm{msec}, \mathrm{p}<0.001)$ and the $90^{\text {th }}$ min post reperfusion ECG $(79.56 \pm 11.22 v s .64 .37 \pm 8.79 \mathrm{msec}$,

\begin{tabular}{|c|c|c|c|}
\hline Parameters & Group A & Group B & $\mathbf{P}$ \\
\hline & $(n=55)$ & $(n=45)$ & \\
\hline Age & $48.18 \pm 8.74$ & $52.62 \pm 8.94$ & $0.014^{*}$ \\
\hline Gender(male) No. (\%) & $42(76.4)$ & $33(73.3)$ & 0.728 \\
\hline Diabetes mellitus No. (\%) & $28(50.9)$ & $25(55.6)$ & 0.643 \\
\hline Hypertension No. (\%) & $14(25.5)$ & $18(40)$ & 0.121 \\
\hline Smoker No. (\%) & $27(49.1)$ & $28(62.2)$ & 0.189 \\
\hline Systolic BP $(\mathrm{mmHg})($ Mean \pm SD) & $131.09 \pm 16.85$ & $135.33 \pm 20.40$ & 0.258 \\
\hline Diastolic BP $(\mathrm{mmHg})($ Mean $\pm \mathrm{SD})$ & $84.55 \pm 10.33$ & $85.33 \pm 9.91$ & 0.99 \\
\hline Heart rate $(\mathrm{bpm})($ Mean $\pm \mathrm{SD})$ & $81.64 \pm 11.67$ & $81.67 \pm 12.84$ & \\
\hline Killip class I & $52(94.5)$ & $40(88.9)$ & \multirow{2}{*}{$0.016^{*}$} \\
\hline Killip class II-III & $3(5.4)$ & $5(11.1)$ & \\
\hline CK-MB $(\mu / \mathrm{dl})($ Mean \pm SD) & $57.32 \pm 64.54$ & $75.48 \pm 69.90$ & 0.041 \\
\hline Troponin I ( $\mu / \mathrm{dl})($ Mean \pm SD) & $69.22 \pm 77.08$ & $84.11 \pm 60.44$ & $0.019^{*}$ \\
\hline $\begin{array}{l}\text { Serum creatinine }(\mathrm{mg} / \mathrm{dl}) \text { (Mean } \\
\qquad \pm \mathrm{SD})\end{array}$ & $1.06 \pm 0.28$ & $1.14 \pm 0.31$ & 0.197 \\
\hline LDL (mg/dl) (Mean \pm SD) & $137.27 \pm 51.19$ & $140.27 \pm 39.73$ & 0.37 \\
\hline $\mathrm{HDL}(\mathrm{mg} / \mathrm{dl})($ Mean $\pm \mathrm{SD})$ & $47.73 \pm 10.10$ & $44.13 \pm 10.34$ & 0.083 \\
\hline Triglycerides (mg/dl) $($ Mean \pm SD) & $204.95 \pm 98.15$ & $194.76 \pm 82.15$ & 0.58 \\
\hline \multicolumn{4}{|c|}{ Myocardial infarction subtypes } \\
\hline Anterior (No.) (\%) & $28(50.9)$ & $26(57.8)$ & \multirow{2}{*}{0.493} \\
\hline Non anterior (No.) (\%) & $27(49.1)$ & $19(42.2)$ & \\
\hline \multicolumn{4}{|c|}{ Method of reperfusion } \\
\hline Fibrinolytic therapy No. (\%) & $16(29.1)$ & $34(75.6)$ & \multirow{2}{*}{$<0.001^{*}$} \\
\hline Primary PCI No. (\%) & $39(70.9)$ & $11(24.4)$ & \\
\hline Pain to needle (hours) (Mean $\pm S D$ ) & $2.87 \pm 1.24$ & $4.33 \pm 1.86$ & $<0.001^{*}$ \\
\hline WMSI (Mean \pm SD) & $1.40 \pm 0.37$ & $1.72 \pm 0.59$ & $0.007^{*}$ \\
\hline Ejection fraction (\%) Mean $\pm \mathrm{SD}$ & $56.60 \pm 7.07$ & $50.67 \pm 10.63$ & $0.002^{*}$ \\
\hline
\end{tabular}

BP: Blood Pressure; HDL: High Density Lipoprotein; LDL: Low Density Lipoprotein; PCl: Percutaneous Coronary Intervention; WMSI: Wall Motion Score Index

Table 1: Comparison between the two studied groups according to baseline data

\begin{tabular}{|c|c|c|c|c|c|}
\hline \multirow{3}{*}{ Angiographic characteristics } & \multirow{2}{*}{\multicolumn{2}{|c|}{$\begin{array}{c}\text { Group A } \\
(n=55)\end{array}$}} & \multirow{2}{*}{\multicolumn{2}{|c|}{$\begin{array}{c}\text { Group B } \\
(n=45)\end{array}$}} & \multirow{3}{*}{$P$ value } \\
\hline & & & & & \\
\hline & No. & $\%$ & No. & $\%$ & \\
\hline \multicolumn{6}{|c|}{ TIMI } \\
\hline $0-1$ & 2 & 3.6 & 25 & 55.6 & \multirow{2}{*}{$<0.001^{*}$} \\
\hline $2-3$ & 53 & 96.4 & 20 & 44.4 & \\
\hline \multicolumn{6}{|c|}{ Numbers of other diseased vessels } \\
\hline One vessel & 22 & 40 & 14 & 31.1 & \multirow{3}{*}{0.325} \\
\hline Two vessel & 18 & 32.7 & 19 & 42.2 & \\
\hline Three vessel & 15 & 27.2 & 12 & 26.7 & \\
\hline \multicolumn{6}{|c|}{ Infarct related artery } \\
\hline LAD & 25 & 45.5 & 20 & 44.4 & \multirow{3}{*}{0.472} \\
\hline LCX & 16 & 29.1 & 13 & 28.9 & \\
\hline RCA & 14 & 25.4 & 12 & 26.7 & \\
\hline Stent utilization & 45 & 81.8 & 30 & 66.6 & $0.045^{\star}$ \\
\hline
\end{tabular}

TIMI: Thrombolysis In Myocardial Infarction; LAD: Left Anterior Descending; LCX: Left Circumflex; RCA: Right Coronary Artery

Table 2: The angiographic characteristics of the studied groups. 
$\mathrm{p}<0.001)$. When the amount of change in $\mathrm{QRS}$ duration post reperfusion was taken into account, a significant difference was detected between the two groups post-reperfusion at both the $60^{\text {th }} \min (0.44 \pm 1.79 v s$. $11.73 \pm 8.12 \mathrm{msec}, \mathrm{p}<0.001)$ and the $90^{\text {th }}$ min ECG $(0.44 \pm 1.97$ vs. 13.91 $\pm 9.94 \mathrm{msec}, \mathrm{p}<0.001)$.

On correlation analysis there was a strong positive correlation between 60 min and 90 min QRS complex narrowing and MBG $(r=0.731$ and 0.739 respectively, $\mathrm{p}<0.001$ for both) Figure 1 , and there was a strong negative correlation between pain to needle time and $60 \mathrm{~min}$ and 90 min QRS complex narrowing ( $\mathrm{r}=-0.367$ and -0.360 respectively, $\mathrm{p}<0.001$ for both) Figure 2. Roc analysis was performed to determine the best cut off value of the QRS duration post reperfusion at $60^{\text {th }}$ and $90^{\text {th }}$ min for predicting reperfusion, we found that QRS complex narrowing of $10 \mathrm{msec}$ at $60 \mathrm{~min}$ and $90 \mathrm{~min}$ post reperfusion was determined to be the best discriminating value for reperfusion assessment, at 60 min (AUC $=0.89$, sensitivity $100 \%$, specificity $43.64 \%, \mathrm{p}<0.001$ ), and at $90 \mathrm{~min}(\mathrm{AUC}=0.88$, sensitivity $100 \%$, specificity $58.18 \%, \mathrm{p}<0.001)$ as shown in Figure 3, also QRS complex duration cut off of $65 \mathrm{msec}$ at both $60 \mathrm{~min}$ and $90 \mathrm{~min}$ post reperfusion was determined to be the best discriminating value for reperfusion assessment, at $60 \mathrm{~min}$ (AUC $=0.79$, sensitivity $80 \%$, specificity $67.27 \%, \mathrm{p}<0.001$ ), and at 90

\begin{tabular}{|c|c|c|c|}
\hline Electrocardiographic findings & $\underset{(n=55)}{\text { Group A }}$ & $\begin{array}{c}\text { Group B } \\
(n=45)\end{array}$ & $P$ value \\
\hline Sum ST elevation on admission (mm) & $7.93 \pm 4.10$ & $10.71 \pm 6.89$ & 0.094 \\
\hline Sum ST depression on admission (mm) & $2.64 \pm 2.68$ & $3.41 \pm 4.53$ & 0.699 \\
\hline ST deviation score on admission & $10.62 \pm 4.66$ & $14.03 \pm 7.28$ & $0.028^{*}$ \\
\hline $\begin{array}{l}\text { Sum of ST elevation at } 60 \text { min ECG } \\
\qquad(\mathrm{mm})\end{array}$ & $3.23 \pm 2.99$ & $7.58 \pm 6.45$ & $<0.001^{*}$ \\
\hline $\begin{array}{l}\text { Sum of ST depression at } 60 \text { min ECG } \\
\qquad(\mathrm{mm})\end{array}$ & $0.58 \pm 0.94$ & $2.38 \pm 3.0$ & $<0.001^{*}$ \\
\hline $\begin{array}{l}\text { ST deviation score at } 60 \text { min ECG } \\
(\mathrm{mm})\end{array}$ & $3.81 \pm 3.03$ & $9.92 \pm 7.23$ & $<0.001^{*}$ \\
\hline $\begin{array}{l}\text { Sum of ST elevation at } 90 \text { min ECG } \\
\qquad(\mathrm{mm})\end{array}$ & $1.91 \pm 2.76$ & $5.73 \pm 5.75$ & $<0.001^{*}$ \\
\hline $\begin{array}{l}\text { Sum of ST depression at } 90 \text { min ECG } \\
\qquad(\mathrm{mm})\end{array}$ & $0.16 \pm 0.54$ & $1.42 \pm 2.29$ & $<0.001^{*}$ \\
\hline $\begin{array}{l}\text { ST deviation score at } 90 \text { min ECG } \\
(\mathrm{mm})\end{array}$ & $2.07 \pm 2.81$ & $7.13 \pm 6.14$ & $<0.001^{*}$ \\
\hline Admission QRS duration (msec) & $78.64 \pm 11.72$ & $78.0 \pm 11.30$ & 0.859 \\
\hline QRS duration at 60 min ECG (msec) & $66.55 \pm 9.71$ & $78.44 \pm 11.37$ & $<0.001^{*}$ \\
\hline QRS duration at 90 min ECG (msec) & $64.37 \pm 8.79$ & $79.56 \pm 11.22$ & $<0.001^{*}$ \\
\hline QRS narrowing at 60 min ECG (msec) & $11.73 \pm 8.12$ & $0.44 \pm 1.79$ & $<0.001^{*}$ \\
\hline QRS narrowing at 90 min ECG (msec) & $13.91 \pm 9.94$ & $0.44 \pm 1.97$ & $<0.001^{*}$ \\
\hline ECG: Electrocardiogram & & & \\
\hline
\end{tabular}

Table 3: Electrocardiographic findings of the studied groups.

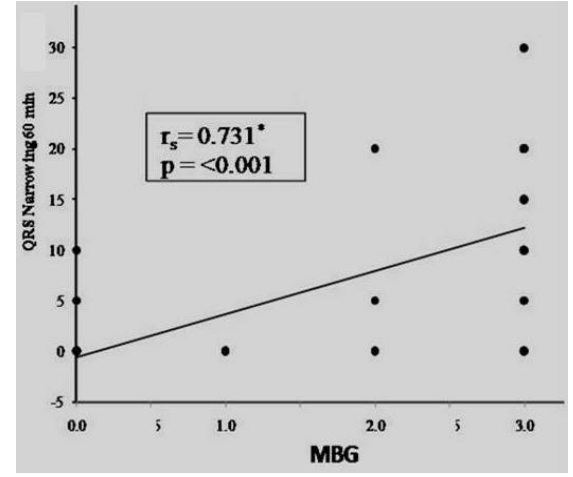

Figure 1: Correlation between QRS complex narrowing and myocardial blush grade (MBG), at $60 \mathrm{~min}$ post reperfusion.

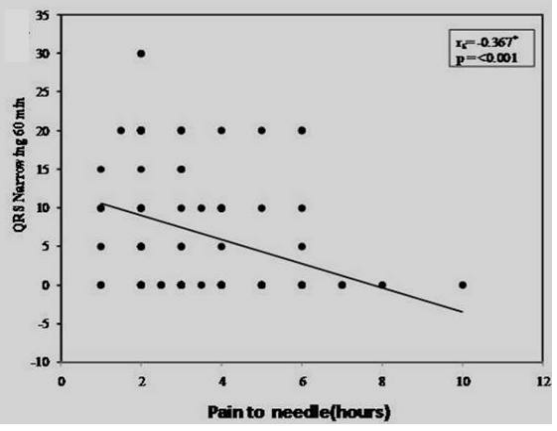

Figure 2: Correlation between QRS complex narrowing and pain to needle at 60 min post reperfusion.

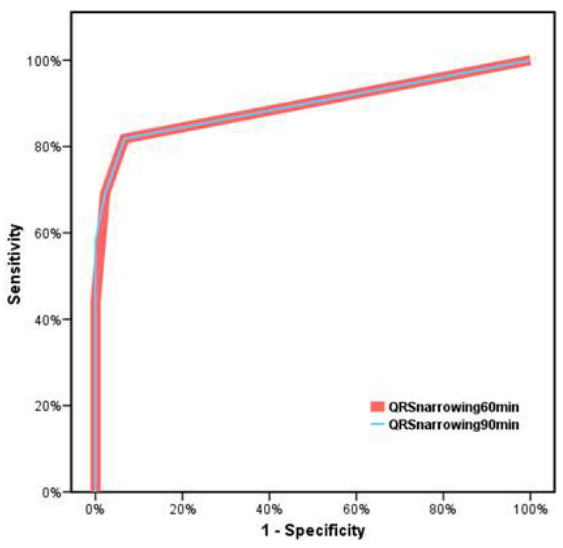

Figure 3: ROC curve showing the sensitivity and specificity of the QRS complex narrowing cut off $10 \mathrm{msec}$ for assessment of reperfusion at 60 and $90 \mathrm{~min}$ post reperfusion.

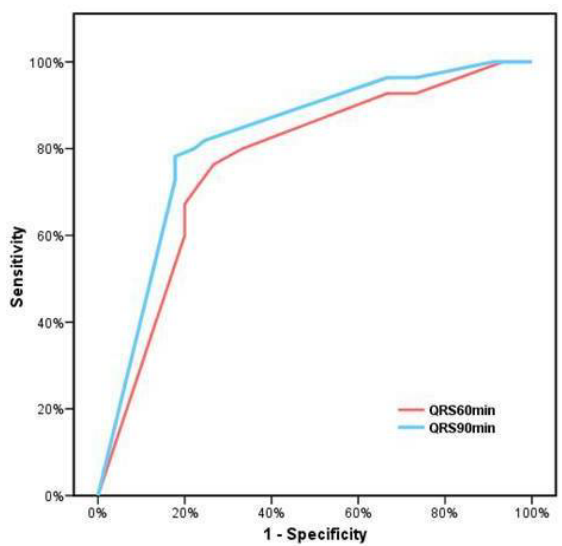

Figure 4: ROC curve showing the sensitivity and specificity of the QRS complex duration cut off $65 \mathrm{msec}$ for assessment of reperfusion at 60 and 90 min post reperfusion.

min $(\mathrm{AUC}=0.822$, sensitivity $82.22 \%$, specificity $78.18 \%, \mathrm{p}<0.001)$ as shown in Figure 4.

\section{Discussion}

Although ST segment deflections have been widely utilized as a means of assessing the degree of underlying ischemic injury, the relationship of QRS complex alterations to the ischemic process is poorly understood. Prolongation of QRS that occurs during acute coronary 
obstruction is mostly due to slowing of conduction within the ischemic areas and this mechanism was proved in several experimental models and human studies [17-20]. In our study, we analyzed QRS complex duration changes on admission, at 60 and 90 min post reperfusion and we found that there is no significant difference between the two groups regarding the admission QRS but there is a significant prolongation of the QRS duration in 60 min and 90 min post reperfusion ECG in the group with impaired perfusion compared to group with a successful perfusion and our findings are in agreement with several published studies. Cantor et al. [21], in his study had measured the QRS duration in 51 patients undergoing elective PCI and concluded that QRS prolongation was an ischemia marker in most patients during PCI and was more sensitive than chest pain or ST-T changes. Erdogan et al. [22], enrolled 148 patients presented with STEMI and treated by primary PCI, the patients in the impaired reperfusion group had a significantly longer QRS duration both at immediate post-angioplasty (78 $\pm 18 v s$. $68 \pm 17 \mathrm{msec}, \mathrm{p}=0.001)$ and at the $60^{\text {th }}$ min ECG $(77 \pm 17 v s .60 \pm 17$ $\mathrm{msec}, \mathrm{p}<0.001)$ and after adjusting all variables, $Q R S$ narrowing in the $60^{\text {th }}$ min ECG was determined as an independent electrocardiographic predictor of reperfusion, his findings are in much agreements with our study findings, also Tsukahra et al. [23] reported QRS duration normalization within $24 \mathrm{~h}$ following successful angioplasty in $79 \%$ of patients having intermediately prolonged QRS duration on admission that suggest that the QRS prolongation on presenting ECG might have been caused primarily by extensive ischemia and poor metabolic state, rather than by myocardial fibrosis and increased myocardial mass, which are associated with persistent QRS prolongation.

In our study, there was a strong negative correlation between pain to needle time and 60 and 90 min QRS narrowing duration and this indicate that prolonged ischemia and delayed reperfusion leads to QRS prolongation and this was investigated by Henriques JP et al. [24], as they found that delayed reperfusion results in thrombus organization with distal embolization that will decrease the QRS narrowing post reperfusion.

\section{Conclusion}

QRS duration changes post reperfusion is strongly correlated to myocardial reperfusion in patients presenting with STEMI.

\section{Study Limitations}

One of the limitations in this study is the small sample size, and measuring the QRS by manual methods instead of the automatic methods but we did that because the manual method was more accurate in presence of the ST segment elevation, also measuring QRS duration for every STEMI patient on admission and after revascularization, is not standard in clinical practice.

\section{Conflict of Interest}

None declared.

\section{References}

1. Fuster V, Moreno PR, Fayad ZA, Corti R, Badimon J (2005) Atherothrombosis and high risk plaque: part 1: evolving concepts. J Am Coll Cardiol 46: 937-954.

2. O'Gara PT, Kushner FG, Ascheim DD, Casey DE, Chung MK, et al. (2013) ACCF/AHA Guideline for the Management of ST-Elevation Myocardial Infarction. JACC 61: e78-140.

3. Pedoe TH, Kuulasmaa K, Amouyel P, Arveiler D, Rajakangas AM, et al. (1994) Myocardial infarction and coronary deaths in the World Health Organization MONICA Project. Circulation 90: 583-612.

4. Surawicz B (1998) Reversible QRS changes during acute myocardial ischemia J Electrocardiol 31: 209-220.
5. Brilakis ES, Mavrogiorgos NC, Kopecky SL, Rihal CC, Gersh BJ, et al. (2002) Usefulness of QRS duration in the absence of bundle branch block as an early predictor of survival in non- ST elevation acute myocardial infarction. Am J Cardiol 89: 1013-1018.

6. Lang RM, Badano LP, Mor-Avi V, Afilalo J, Armstrong A, et al. (2015) Recommendations for Cardiac Chamber Quantification by Echocardiography in Adults: An Update from the American Society of Echocardiography and the European Association of Cardiovascular Imaging. Euro Heart J Cardiovascular Imag 16: 233-271.

7. Saski K, Yotsukura M, Sakata K, Yoshino H, Ishikawa K (2001) Relation of ST-segment changes in inferior leads during anterior wall acute myocardial infarction to length and occlusion site of the left anterior descending coronary artery. Am J Cardiol 87: 1340-1345.

8. Zimetbaum PJ, Josephson ME (2003) Use of the electrocardiogram in acute myocardial infarction. N Engl J Med 348: 933-940.

9. Atar S, Barbagelata A, Birnbaum Y (2006) Electrocardiographic diagnosis of ST-elevation myocardial infarction. Cardiol Clin 24: 343-365.

10. Eskola MJ, Nikus KC, Holmvang L, Sclarovsky S, Tilsted HH, et al. (2009) Value of the 12-lead electrocardiogram to define the level of obstruction in acute anterior wall myocardial infarction: correlation to coronary angiography and clinical outcome in the DANAMI-2 trial. Int J Cardiol 131: 378-83.

11. Wang SS, Paynter I, Kelly RV, Gorgels AP, Wellens HJ (2009) Electrocardiographic determination of culprit lesion site in patients with acute coronary events. J Electrocardol 42: 46-51.

12. Palmeri ST, Harrison DG, Cobb FR, Morris KG, Harrell FE, et al. (1982) A QRS scoring system for assessing left ventricular function after myocardial infarction. N Engl J Med 306: 4-9.

13. Fioretti P, Brower RW, Lazzeroni E, Simoons ML, Wijns W, et al. (1985) Limitations of a QRS scoring system to assess left ventricular function and prognosis at hospital discharge after myocardial infarction. Br Heart $\mathrm{J} 53$ : 248-252.

14. Murkofsky RL, Dangas G, Diamond JA, Mehta D, Schaffer A, et al. (1998) A prolonged QRS duration on surface electrocardiogram is a specific indicator of left ventricular dysfunction. J Am Coll Cardiol 32: 476-482.

15. The TIMI Study Group (1985) The Thrombolysis in Myocardial Infarction (TIMI) Trial. N Engl J Med 31: 932-936.

16. Van't Hof AWJ, Liem A, Suryapranata H, Hoorntje CA, Jan de Boer M, et al (1998) Angiographic assessment of myocardial reperfusion in patients treated with primary angioplasty for acute myocardial infarction: myocardial blush grade: Zwolle Myocardial Infarction Study Group. Circulation 97: 2302-2306.

17. Weston P, Johanson P, Schwartz LM, Maynard C, Jennings RB, et al. (2007) The value of both ST-segment and QRS complex changes during acute coronary occlusion for prediction of reperfusion- induced myocardial salvage in a canine model. J Electrocardiol 40: 18-25.

18. Mendez C, Mueller WJ, Meredith J, Moe GK (1969) Interaction of transmembrane potentials in canin purkinje fibers and at purkinje fibermuscle junctions. Circ Res 24: 361-372.

19. Hamlin RL, Pipers FS, Hellerstein HK, Smith CR (1968) QRS alterations immediately following production of left ventricular free-wall ischemia in dogs. Am J Physiol 215: 1032-1040.

20. Grant RP, Dodge HT (1956) Mechanisms of QRS complex prolongation in man: Left ventricular conduction disturbances. Am J Med 20: 834-852.

21. Cantor AA, Goldfarb B, llia R (2000) QRS prolongation: a sensitive marker of ischemia during percutaneous transluminal coronary angioplasty. Catheter Cardiovasc Interventions 50: 177-183.

22. Ilkay E, Kacmaz1 F, Maden O, Aksu T, Mehmet-Timur Selcuk, et al. (2012) A new electrocardiographic marker of myocardial reperfusion in patients with acute ST-segment elevation myocardial infarction treated with primary percutaneous intervention: the value of QRS duration. Eurolntervention 7: 1406-1412.

23. Tsukahara K, Kimura K, Kosuge M, Shimizu T, Sugano T, et al. (2005) Clinica implications of intermediate QRS prolongation in the absence of bundle-branch block in patients with ST-segment-elevation acute myocardial infarction. Circ J 69: 29-34.

24. Henriques JP, Zijlstra F, Ottervanger JP, de Boer MJ, van 't Hof AW, et al. (2002) Incidence and clinical sig $\urcorner$ nificance of distal embolization during primary angioplasty for acute myocardial infarction. Eur Heart J 23: 1112-1117. 